\title{
HUBUNGAN KADAR TIMBAL DALAM DARAH DENGAN TEKANAN DARAH PADA PEKERJA BENGKEL KENDARAAN DI KECAMATAN TAMPAKSIRING, KABUPATEN GIANYAR TAHUN 2019
}

\section{THE CORRELATION OF BLOOD LEAD LEVELS AND BLOOD PRESSURE IN VEHICLE REPAIR SHOP WORKERS IN TAMPAKSIRING DISTRICT, GIANYAR REGENCY, 2019}

\author{
Ni Luh Nova Dilisca Dwi Putri ${ }^{1}$, Sri Idayani² \\ Teknologi Laboratorium Medis, STIKes Wira Medika Bali
}

\begin{abstract}
ABSTRAK
Logam pencemar dari kendaraan dengan bahan bakar bensin bertimbal bisa terakumulasi dalam tubuh, menyerang organ-organ penting, bahkan merusak kualitas keturunan. Keracunan timbal $(\mathrm{Pb})$ dapat dialami oleh pekerja bengkel melalui asap kendaraan yang sedang diperbaiki. Keracunan kronik timbal $(\mathrm{Pb})$ yang paling sering adalah kelemahan, anoreksia, keguguran, tremor, turunnya berat badan, sakit kepala dan gejala saluran pencernaan. Timbal yang masuk dalam aliran darah dapat menyebabkan hipertensi, hal ini disebabkan karena timbal dapat menyebabkan meningkatnya produksi reactive oxygen species (ROS). Penelitian ini bertujuan untuk untuk mengetahui adanya hubungan antara adanya kandungan kadar timbal dalam darah dengan terjadinya hipertensi pada pekerja bengkel. Pemeriksaan kadar timbal dalam darah dilakukan dengan menggunakan alat MPAES dan pemeriksaan tekanan darah dilakukan dengan menggunakan alat tensimeter digital. Hasil penelitian menunjukkan bahwa terdapat hubungan antara kadar timbal dalam darah dengan tekanan darah pada pekerja bengkel di Kabupaten Gianyar pada Tahun 2019 dengan uji korelasi bivariate pearson menghasilkan sig. (2-tailed) sebesar $0.008<0.05$ menunjukkan adanya korelasi antara variabel kadar timbal dalam darah dengan tekanan darah (hipertensi).
\end{abstract}

Kata Kunci: Timbal dalam darah, Tekanan Darah, Pekerja bengkel kendaraan. 


\begin{abstract}
Pollutant metals from vehicles with leaded gasoline can accumulate in the body, attack important organs, and even damage the quality of offspring. Lead poisoning $(\mathrm{Pb})$ can be experienced by workshop workers through vehicle fumes that are being repaired. Chronic lead poisoning $(\mathrm{Pb})$ most often is weakness, anorexia, miscarriage, tremors, weight loss, headaches and digestive tract symptoms. Lead entering the bloodstream can cause hypertension, this is because lead can lead to increased production of reactive oxygen species (ROS). This study aims to determine the relationship between the content of lead levels in blood with the occurrence of hypertension in workshop workers. Examination of blood lead levels is carried out using MPAES tools and blood pressure checks are carried out using digital tensimeter devices. The results showed that there was a correlation between blood lead levels and blood pressure in workshop workers in Gianyar Regency in 2019 with the bivariate Pearson correlation test producing sig. (2-tailed) of 0.008 $<0.05$ showed a correlation between variable levels of lead in blood with blood pressure (hypertension).

Keywords: Lead in blood, Blood Pressure, Vehicle repair shop workers.

\begin{tabular}{ll}
\hline Alamat Korespondensi & $:$ STIKES Wira Medika Bali \\
Email & $: \underline{\text { nova diliscacute@yahoo.com }}$ \\
\hline
\end{tabular}
\end{abstract}

\title{
PENDAHULUAN
}

Timbal $(\mathrm{Pb})$ atau plumbum merupakan salah satu pencemar di udara memiliki bentuk partikel yang sering dikenal dengan debu metalik. Timbal biasa digunakan sebagai campuran bahan bakar bensin yang berfungsi meningkatkan efisiensi pembakaran. Jumlah senyawa timbal lebih besar (62\%) dibandingkan senyawa lain, dan timbal tidak mengalami proses pembakaran yang sempurna menyebabkan jumlah timbal yang dibuang ke udara melalui asap buangan kendaraan sangat tinggi (Palar, 2008). Timbal yang terbuang lewat knalpot adalah satu diantara zat pencemar diudara (Samsuar \& Pebrice, 2017).

Timbal dapat masuk ke dalam tubuh melalui berbagai cara yaitu melalui saluran pernafasan (inhalasi), saluran pencernaan (oral), maupun kontak kulit (dermal). Timbal yang terhirup dan masuk melalui sistem pernafasan akan ikut beredar melalui darah ke seluruh jaringan dan organ tubuh, selanjutnya akan mengendap di dalam darah (Candra, Setiani, \& Hanani, 2016).

Logam berat timbal bisa terakumulasi dalam tubuh dan menyerang organorgan penting, bahkan merusak kualitas keturunan (Palar, 2008). Keracunan kronik timbal $(\mathrm{Pb})$ juga menyebabkan kelemahan, anoreksia, keguguran, tremor, turunnya berat badan, sakit kepala dan gejala saluran pencernaan. Selain itu, timbal juga dapat menyebabkan terjadinya hipertensi. Terjadinya hipertensi dapat disebabkan karena timbal dapat menyebabkan meningkatnya produksi Reactive Oxygen Species (ROS). ROS merupakan bentuk turunan dari oksigen yang terjadi saat bereaksi dengan elektron. Sumber utama $R O S$ adalah oksigen yang terjadi saat 
bereaksi dengan elektron. ROS dapat meningkatkan tekanan darah secara langsung dan mempengaruhi perubahan atherosclerotic dalam darah yang menyebabkan meningkatnya tekanan pembuluh darah arteri dan gangguan jantung (Farmand, Ehdaie, Roberts, \& Sindhu, 2005).

Paparan timbal $(\mathrm{Pb})$ kronis juga dapat menyebabkan oxidative stress meningkat, sehingga mengakibatkan inflamasi dan mengganggu kerja nitric oxide (NO) yang berfungsi untuk memperlebar arteri dan mengatur tekanan darah. Kemudian akibatnya yaitu terganggunya kerja dari $N O$, pada akhirnya memicu proses terjadinya hipertensi pada keracunan kronis karena adanya akumulasi timbal (Pb) dalam darah pada orang dewasa (Alghasham, Meki, \& Ismail, 2011).

Penelitian di Amerika mendapatkan bahwa keracunan akut timbal memberikan efek terhadap tekanan darah dan pada keracunan kronis menimbulkan hipertensi karena adanya akumulasi timbal di dalam darah pada orang dewasa (Martin, 2009). Efek paparan timbal pada hipertensi biasanya terjadi karena paparan kerja yang berlebihan dapat menimbulkan efek gangguan fungsi ginjal sehingga gangguan fungsi ginjal tersebut dapat berpengaruh pada tekanan darah. Timbal memiliki efek langsung dan tidak langsung pada pembuluh darah dan kontraktilitas otot polos sehingga dapat memengaruhi tekanan darah (AOEC, 2007).

Paparan timbal sangat dirasakan oleh kelompok masyarakat yang sering dan lama kontak terhadap sumber pencemaran timbal yang disebut sebagai masyarakat resiko tinggi, salah satu pekerjaan yang beresiko terhadap pencemaran timbal adalah pekerja bengkel kendaraan (Samsuar \& Pebrice, 2017). Menurut Ramadhani (2018) keracunan timbal $(\mathrm{Pb})$ dapat dialami oleh pekerja bengkel melalui asap kendaraan yang sedang diperbaiki. Berdasarkan penelitian Dongre, Nilima, dan Suryakar (2011) menyatakan bahwa paparan $\mathrm{Pb}$ pada pekerja bengkel mobil dapat meningkatkan tekanan darah sistolik sebesar 5,32\% dan tekanan darah diastolik sebesar 5,87\%.

Pasorong, Mery, Haripurnomo, dan Nawi (2007) berdasarkan hasil penelitiannya menjelaskan bahwa ada hubungan antara kadar timbal $(\mathrm{Pb})$ dalam darah dengan terjadinya hipertensi. Hal ini erat kaitannya dengan adanya polutan timbal $(\mathrm{Pb})$ sebagai akibat dari meningkatnya kepadatan kendaraan bermotor dan masih rendahnya penggunaan APD oleh populasi yang berisiko tinggi terpapar polutan timbal $(\mathrm{Pb})$.

Berdasarkan latar belakang diatas dan manfaat penelitian yang dapat memberikan informasi mengenai dampak bahaya timbal $(\mathrm{Pb})$ bagi kesehatan serta dapat memberikan informasi tentang pengaruh kadar timbal dalam darah terhadap kenaikan tekanan darah (hipertensi). Maka peneliti melakukan penelitian mengenai Hubungan Kadar Timbal Dalam Darah Dengan Tekanan Darah Pada Pekerja Bengkel Kendaraan Tahun 2019.

\section{METODE PENELITIAN}

Pengambilan sampel dilakukan di bengkel mobil dan motor di Kabupaten Gianyar. Untuk pemeriksaan kadar Timbal darah dilakukan di laboratorium Forensik Denpasar, dan pemeriksaan tekanan darah dilakukan di lokasi masingmasing bengkel yang berlokasi di Kabupaten Gianyar dengan menggunakan alat tensimeter digital. Penelitian ini dilaksanakan pada bulan Januari - Juli 2019. 
Jenis penelitian yang di gunakan dalam penelitian ini adalah penelitian deskriptif korelatif dengan pendekatan cross sectional study yang bertujuan untuk mengetahui hubungan antara kadar timbal dalam darah dengan tekanan darah pada pekerja bengkel kendaraan di Kabupaten Gianyar pada tahun 2019.

Adapun populasi dalam penelitian ini adalah pekerja bengkel mobil dan motor di Kabupaten Gianyar yang melakukan pekerjaan di bengkel mobil dan motor pada sejumlah 5 bengkel. Sampel darah yang diambil dari pekerja bengkel mobil dan motor yang ada di Kabupaten Gianyar dengan kriteria masa kerja lebih dari 5 tahun.

Pengambilan sampel dalam penelitian ini dilakukan dengan Teknik Purposive Sampling yang berarti memilih subyek penelitian berdasarkan ciri-ciri khusus yang sesuai dengan tujuan penelitian (Chandra, 2008). Kriteria inklusi dan eksklusi dalam penelitian ini adalah sebagai berikut:

Kriteria inklusi adalah kriteria dimana subjek penelitian dapat mewakili dalam sampel penelitian yang memenuhi syarat sebagai sampel (Notoatmodjo, 2002). Kriteria inklusi dalam penelitian ini adalah:

1. Memiliki masa kerja $>5$ tahun

2. Bekerja sebagai pekerja bengkel kendaraan mobil dan motor

3. Bersedia menjadi respoden

Kriteria eksklusi merupakan kriteria dimana subjek penelitian tidak dapat mewakili sampel karena tidak memenuhi syarat sebagai sampel penelitian (Notoatmodjo, 2002). Pekerja bengkel mobil dan motor yang memiliki masa kerja $<5$ tahun dan sedang mengkonsumsi obat atau sedang sakit. Sehingga berdasarkan kriteria inklusi tersebut, maka diperoleh sebanyak 8 sampel.

Data primer yang mencakup variabel-variabel yang diteliti diperoleh pada sampel menggunakan instrumen kuesioner sebagai alat untuk wawancara yang terpilih sebagai subyek penelitian, dan pengukuran kadar $\mathrm{Pb}$ dalam darah dan tekanan darah pada pekerja bengkel kendaraan mobil dan motor di Kabupaten Gianyar. Data sekunder meliputi gambaran umum lokasi penelitian dan juga diperoleh dari literatur-literatur perpustakaan, artikel yang berkaitan dengan penelitian.

\section{HASIL DAN PEMBAHASAN}

\section{Hasil Penelitian}

Tabel 1. Hasil Pengukuran Kadar Timbal (Pb) Dalam Darah dan Tekanan Darah Pada Pekerja Bengkel Kendaraan

\begin{tabular}{|c|c|c|c|c|c|}
\hline Sampel & $\begin{array}{c}\text { Hasil Pengukuran } \\
\text { Pb ( ppm ) }\end{array}$ & $\begin{array}{l}\text { Nilai ambang } \\
\text { batas } \mathrm{Pb} \\
\text { ( ppm ) }\end{array}$ & Keterangan & $\begin{array}{l}\text { Tekanan } \\
\text { Darah } \\
(\mathrm{mmHg})\end{array}$ & Keterangan \\
\hline 1. & 0,29 & $0,1-0,25$ & $\begin{array}{l}\text { Melewati } \\
\text { ambang batas }\end{array}$ & $140-159$ & hipertensi \\
\hline 2. & 0,27 & $0,1-0,25$ & $\begin{array}{l}\text { Melewati } \\
\text { ambang batas }\end{array}$ & $158-170$ & hipertensi \\
\hline 3. & 0,24 & $0,1-0,25$ & $\begin{array}{l}\text { Tidak melewati } \\
\text { ambang batas }\end{array}$ & $80-110$ & Normal \\
\hline 4. & 0,30 & $0,1-0,25$ & $\begin{array}{l}\text { Melewati } \\
\text { ambang batas }\end{array}$ & $149-160$ & hipertensi \\
\hline
\end{tabular}


Bali Medika Jurnal.

Vol 8 No 1, 2021: 82-89

ISSN : 2615-7047

DOI: https://doi.org/10.36376/bmj.v8i1

\begin{tabular}{ccclcc}
\hline 5. & 0,11 & $0,1-0,25$ & $\begin{array}{l}\text { Tidak melewati } \\
\text { ambang batas }\end{array}$ & $90-120$ & Normal \\
\hline 6. & 0,16 & $0,1-0,25$ & $\begin{array}{l}\text { Tidak melewati } \\
\text { ambang batas }\end{array}$ & $90-118$ & Normal \\
\hline 7. & 0,09 & $0,1-0,25$ & $\begin{array}{l}\text { Tidak melewati } \\
\text { ambang batas }\end{array}$ & $90-115$ & Normal \\
\hline 8. & 0,11 & $0,1-0,25$ & $\begin{array}{l}\text { Tidak melewati } \\
\text { ambang batas }\end{array}$ & $108-120$ & Normal \\
\hline
\end{tabular}

\section{Diskusi Hasil}

Pengukuran kadar timbal dalam sampel darah yang telah dilakukan menunjukkan dari delapan pekerja bengkel kendaraan memberikan hasil bahwa 3 pekerja memiliki hasil pemeriksaan kadar timbal dalam darah melebihi ambang batas yaitu pada sampel 1, 2, dan 4 dengan hasil sebagai berikut $(0,29 ; 0,27 ; 0,30)$ ppm. Pemeriksaan tekanan darah yang telah dilakukan menunjukkan dari delapan pekerja bengkel memberikan hasil bahwa 3 pekerja memiliki hasil pemeriksaan tekanan darah tinggi (hipertensi) yaitu pekerja bengkel nomer 1, 2 dan 4 dengan hasil masing-masing sebagai berikut (140-159; 158-170; 149-160) mmHg. Berdasarkan hasil tersebut menunjukkan adanya kadar timbal yang melebihi ambang batas normal dan menyebabkan terjadinya hipertensi, hal tersebut terlihat pada sampel 1, 2, dan 4 .

Terjadinya hipertensi disebabkan karena timbal dapat menyebabkan meningkatnya produksi Reactive Oxygen Species (ROS). ROS merupakan bentuk turunan dari oksigen yang terjadi saat bereaksi dengan electron. Sumber utama ROS adalah oksigen yang terjadi saat bereaksi dengan elektron. Reactive Oxygen Species (ROS) dapat meningkatkan tekanan darah secara langsung dan mempengaruhi perubahan atherosclerotic dalam darah yang menyebabkan meningkatnya tekanan pembuluh darah arteri dan gangguan jantung (Farmand et al., 2005). Adanya timbal $\mathrm{Pb})$ dalam darah dapat menurunkan kemampuan darah mengikat oksigen, mengakibatkan besarnya curah jantung sehingga terjadi peningkatan tekanan darah sistolik, serta besarnya resistensi (tahanan) perifer yang menyebabkan peningkatan tekanan darah diastolik, dan pada akhirnya mengakibatkan timbulnya hipertensi (Azizah. \& Fibrianti., 2014).

Hasil penelitian ini sejalan dengan Pasorong, Mery et al. (2007) menyatakan bahwa kadar timbal dalam darah berhubungan dengan hipertensi pada polisi lalu lintas dengan nilai OR sebesar 6,50 yang artinya polisi yang mempunyai kadar $\mathrm{Pb}$ dalam darah $\geq 6,27 \mu \mathrm{g} / \mathrm{dL}$ dapat berisiko menderita hipertensi 6,5 kali dengan polisi yang mempunyai kadar $\mathrm{Pb}$ dalam darah sebesar $<6,27 \mu \mathrm{g} / \mathrm{dL}$ sehingga dapat dibuktikan bahwa orang yang terpapar polutan $\mathrm{Pb}$ dengan konsentrasi yang tinggi memiliki risiko hipertensi lebih tinggi dibandingkan orang yang terpapar polutan $\mathrm{Pb}$ dengan konsentrasi yang rendah. Hal ini juga sejalan dengan penelitian Rosyidah dan Djannah (2010) berdasarkan hasil penelitian yang dilakukan pada 25 responden didapatkan responden yang menderita hipertensi sebesar sebesar 13 responden (57\%), sedangkan yang tidak menderita hipertensi sebesar 12 responden (48\%), adapun kejadian hipertensi tersebut merupakan faktor resiko dari adanya kandungan $\mathrm{Pb}$ dalam darah.

Uji statistik melalui uji normalitas menggunakan one-sampel KolmogorofSmirnov Test didapatkan hasil nilai Asymp.Sig. (2-tailed) kadar timbal 0.868 dan 
tekanan darah 0.174 nilai tersebut lebih besar dari 0.05 maka hasil tersebut berdistribusi normal, yang dilanjutkan dengan uji homogenitas menggunakan Leavene Statistic dengan hasil sig. 0.111 nilai tersebut $>0.05$. Dilanjutkan dengan uji korelasi bivariate pearson dengan hasil sig. (2-tailed) sebesar $0.008<0.05$ menunjukkan adanya korelasi antara variable kadar timbal dalam darah dengan tekanan darah tinggi (hipertensi).

Tingginya kadar timbal pada sampel 1, 2, dan 4 kemungkinan selain diakibatkan oleh paparan timbal dari asap kendaraan yang sedang diperbaiki, tidak menggunakan APD selama bekerja, bahkan dapat juga disebabkan karena responden memiliki kebiasaan merokok. Berdasarkan penelitian yang telah dilakukan oleh Pratiwi dkk, 2015, disebutkan bahwa responden yang memiliki kebiasaan merokok kadar timbal dalam darahnya termasuk kategori diatas normal dan bahkan semakin banyak jumlah rokok yang dihisap setiap harinya akan semakin tinggi pula kadar timbal dalam darahnya. Kebiasaan merokok memiliki hubungan yang sangat kuat dengan peningkatan kadar timbal dalam darah dan akan menambah resiko kesehatan seperti hipertensi (tekanan darah tinggi). Kemungkinan hal tersebut yang menyebabkan dari 8 responden pekerja bengkal, hanya 3 responden yang memiliki hasil kadar timbal diatas ambang batas.

Berdasarkan hal tersebut, maka diharapkan kesadaran pekerja bengkel untuk menjaga kebersihan diri dengan cara rajin mencuci tangan baik sebelum atau sesudah melakukan pekerjaan terutama bila bersentuhan dengan bahan-bahan yang mengandung timbal seperti minyak pelumas (oli), oli bekas, bensin, dan aki bekas (Putri, 2017). Menggunakan alat pelindung diri (APD) yang dapat meminimalkan kontak langsung dengan bahan-bahan yang mengandung timbal $(\mathrm{Pb})$ sarung tangan dan juga masker pakaian lengan panjang dan alat pelindung kaki pada saat bekerja serta rajin melakukan pemeriksaan darah guna mengetahui kadar logam berat dalam tubuh khususnya logam $\mathrm{Pb}$ (Sakinah, 2011). Disamping hal tersebut, diharapkan juga agar pekerja bengkel menerapkan pola hidup sehat serta menghindari mengkonsumsi rokok.

\section{SIMPULAN DAN SARAN}

Berdasarkan hasil dari penelitian yang telah dilakukan dapat disimpulkan bahwa kadar timbal yang melebihi ambang batas adalah pada sampel nomor 1, 2, 4. masing-masing adalah $(0,29 ; 0,27 ; 0,30) \mathrm{ppm}$, demikian juga dari hasil tekanan darah menunjukkan terjadinya hipertensi pada responden 1, 2, 4 masing-masing adalah (140-159; 158-170; 149-160) mmHg. Hal tersebut menunjukkan adanya hubungan antara tingginya kadar timbal terhadap kejadian hipertensi. Faktor penyebab tingginya kadar timbal pada 3 responden dari total 8 responden kemungkinan dapat disebabkan oleh kebiasaan merokok, dimana faktor merokok juga memiliki hubungan kuat dengan peningkatan kadar timbal dalam darah dan akan menambah resiko kesehatan seperti hipertensi. Berdasarkan hal tersebut, maka saran dari penelitian ini adalah diharapkan kesadaran pekerja bengkel untuk menjaga kebersihan diri dengan cara rajin mencuci tangan sebelum dan sesudah melakukan pekerjaan terutama bila bersentuhan dengan bahan-bahan yang mengandung timbal seperti minyak (oli, bensin, dan aki bekas), selalu 
menggunakan APD (minimal masker). Diharapkan juga agar pekerja bengkel menerapkan pola hidup sehat serta menghindari mengkonsumsi rokok.

\section{UCAPAN TERIMA KASIH}

Ucapan terimakasih peneliti sampaikan kepada Drs. I Dewa Agung Ketut Sudarsana, MM selaku Ketua Sekolah Tinggi Ilmu Kesehatan Wira Medika Bali yang telah memberi kesempatan dan fasilitas kepada penulis untuk mengajukan dan melaksanakan penelitian. Kepada Kepala Pusat Penelitian dan Pengabdian Masyarakat yang telah memberikan kesempatan dan fasilitas kepada penulis untuk mengajukan penelitian. Serta ucapan terimakasih kepada tim peneliti atas kerjasama dan kontribusi yang telah diberikan selama proses penelitian ini.

\section{DAFTAR PUSTAKA}

Alghasham, A. A., Meki, A. R., \& Ismail, H. A. (2011). Association of Blood Lead Level with Elevated Blood Pressure in Hypertensive Patients. International Journal of Health Sciences, 5(1), 17-21.

AOEC. (2007). Association of Occupational and Enviromental Clinics Medical Management Guidelines for Lead-Exposed Adults. Washington DC: Association of Occupational Enviromental Clinics.

Azizah., R., \& Fibrianti., L. D. (2014). Karakteristik, Kadar Timbal (Pb) Dalam Darah, Dan Hipertensi Pekerja Home Industry Aki Bekas Di Desa Talun Kecamatan Sukodadi Kabupaten Lamongan. Surabaya.

Candra, C., Setiani, O., \& Hanani, Y. (2016). Perbedaan Kadar Timbal (Pb) Dalam Darah Sebelum dan Sesudah Pemberian Air Kelapa Hijau (Cocos nucifera L) Pada Pekerja Pengecatan Di Industri Karoseri Semarang. Jurnal Kesehatan Masyarakat, 4(3).

Chandra, B. (2008). Metodologi Penelitian Kesehatan. Jakarta: EGC.

Dongre, N., Nilima, A. N., \& Suryakar. (2011). Biochemical Effects of Lead Exposure on Systolic and Diastolic Blood Pressure, Heme Biosynthesis and Hematological Parameters in Automobile Workers of North Karnataka India. Journal Clinical Biochemical India, 2011, 400-406.

Farmand, F., Ehdaie, A., Roberts, C. H. ., \& Sindhu, R. K. (2005). Lead-Induced Dysregulation of Superoxide Dismutases, Catalase, Glutathione Peroxidase and Guanylate. Environmental Research, 981(2005), 33-39.

Martin, G. T. A. (2009). Association of Blood Lead and Tibia Lead with Blood Pressure and Hypertention in a Community Sample of Older Adults. American. American Journal of Epidemiology, 163(5), 467-478.

Notoatmodjo. (2002). Metodologi Penelitian Kesehatan. Jakarta: Rineka Cipta.

Palar, H. (2008). Pencemaran dan Toksikologi Logam Berat. Jakarta: Rineka Cipta. Pasorong, Mery, B., Haripurnomo, K., \& Nawi, N. (2007). Hubungan Antara Kadar Plumbum $(\mathrm{Pb})$ dan Hipertensi Pada Polisi Lalu Lintas di Kota Manado. Artikel Kesehatan Masyarakat, 23(2).

Putri, R. (2017). Analisa Kadar Timbal (Pb) Dalam Darah Pekerja Bengkel kendaraan Bermotor Roda Dua Di Kota Medan Tahun 2017. Universitas Sumatera Utara. 
Ramadhani, P. (2018). Analisis Paparan Kadar Timbal (Pb) dalam Darah Pekerja Bengkel Kendaraan Bermotor Beroda Dua di Kota Medan. Universitas Sumatera Utara Medan.

Rosyidah, H., \& Djannah, S. N. (2010). Hubungan Antara Kadar Pb Dalam Darah Dengan Kejadian Hipertensi Pada Operator SPBU di Kota Yogyakarta. Jurnal Kesmas, 4(2), 76-143.

Sakinah, R. (2011). Penilaian Resiko Kesehatan dan Keselamatan Kerja di Industri Informal (Bengkel). Universitas Islam Negeri Alauddin.

Samsuar, S. K. M., \& Pebrice, S. (2017). Analisis Kadar Timbal (Pb) pada Rambut Pekerja Bengkel Tambal Ban dan Ikan Mas di Sepanjang Jalan Soekarno-Hata Bandar Lampung Secara Spektrofotometri Serapan Atom. Jurnal Kesehatan, 8(1), 91-97. 